\title{
Uma questão de gênero? A diferença sexual como valor no discurso histórico acerca da histeria
}

\author{
One matter of gender? The sexual difference as a value in the \\ history of hysteria
}

\author{
Gleisson Roberto Schmidt ${ }^{1}$
}

\begin{abstract}
Resumo
Contemporaneamente, vários autores têm se debruçado sobre o tema da "objetividade" da ciência e dos valores científicos. A questão mais básica é a da existência de valores em curso na prática, métodos e produtos da ciência. Este artigo pretende apresentar o discurso histórico acerca da histeria como uma teoria nosológica pautada por valores, sendo estes tanto sociais quanto cognitivos, cuja inter-relação íntima interroga a tese acerca da objetividade dos valores epistêmicos. A histeria afigura, assim, como um exemplo de teoria médico-científica na qual, valores sociais (nomeadamente: valores políticos e religiosos que institucionalizaram uma diferença de gênero) influenciaram decisivamente ora a recusa da existência da entidade mórbida, ora sua descrição e tratamento. Tamanha foi a força dos valores sociais nas teorias etiopatológicas da histeria que, até mesmo na teoria psicanalítica, se ela já não é mais descrita como uma "doença das mulheres", ainda o continua sendo como "sofrimento do feminino".
\end{abstract}

Palavras-chave: Nosologia da histeria. Diferença sexual. Valores sociais. Freud.

\begin{abstract}
Contemporaneously, several authors have been addressing the issue of 'objectivity' of science and scientific values. The most basic question is the existence of values in the current practice, methods and products of science. This article intend to present the historical discourse about hysteria as a nosological theory guided by values which are, at the same time, social and cognitive values, and whose intimate interrelation casts doubt on the thesis of the objectivity of epistemic values. Therefore, the hysteria stands as an example of medical-scientific theory in which social values (including political and religious values that have institutionalized a gender difference) decisively influenced sometimes the rejection of the existence of the disease entity and sometimes its description and treatment. Such it was the strength of social values in the etiopathological theories of hysteria that even in the psychoanalytic theory, if it is no longer described as a 'disease of women', it still remains as a 'female suffering'.
\end{abstract}

Keywords: Nosology of hysteria. Sexual difference. Social values. Freud.

\footnotetext{
${ }^{1}$ Doutorando em Filosofia na Universidade Federal de Santa Catarina. Professor da Universidade Tecnológica Federal do Paraná. E-mail: gleisson.schmidt@gmail.com.
}

Esta obra foi licenciada com uma Licença Creative Commons - Atribuição 3.0 Não Adaptada. 
Contemporaneamente, muitos autores têm se debruçado sobre o tema da "objetividade" da ciência e dos valores científicos. A questão mais básica é a da existência de valores em curso na prática, nos métodos e nos produtos da ciência. Questionam ainda se objetividade e neutralidade científicas são sinônimas, ou se haveria uma dissociação entre elas. Outros se detêm sobre o problema da interrelação entre valores sociais ou morais e valores cognitivos: existe uma influência mútua entre eles? Se sim, sob qual vetor? Valores sociais/morais compõem o escopo dos assim chamados valores epistêmicos, ou são estes que influem nos valores da sociedade?

Um desses autores é o australiano Hugh Lacey (1998). Opondo-se à tese historicamente consagrada segundo a qual a ciência seria um domínio estéril ao subjetivismo do discurso valorativo (em outras palavras, a ciência se pautaria pela objetividade, enquanto que o discurso ético seria essencialmente subjetivo), Lacey (1998) afirma a objetividade dos valores (compreendidos no amplo espectro que inclui os valores morais ou sociais). Essa objetividade tem sua origem na socialização dos mesmos, pela via da institucionalização ou em virtude da sua predominância em determinada sociedade. ${ }^{2}$ É essa objetividade consensual dos valores que permite avaliar o que seria um "juízo científico correto", não a partir de um conjunto de regras, mas "por meio do diálogo entre os membros da comunidade

\footnotetext{
2 Em "Para uma análise dos valores" (1998), após introduzir o problema da polissemia da palavra "valor", Lacey descreve a origem dos valores pessoais e sua inter-relação com os valores sociais. Afirma que os valores pessoais são "dialeticamente tanto produtos quanto pontos de referência de processos com os quais nós refletimos e avaliamos nossos desejos" (LACEY, 1998, p. 40), desejos acerca do futuro (LACEY, 1998, p. 47) e que, relacionados a crenças pessoais ou coletivas, constituem uma parte essencial da explicação da vida prática. Desejos e crenças constituem, então, a "fonte" dos valores pessoais. Sustentar tais valores envolve "o desejo de segunda ordem, o qual representa um dos objetivos fundamentais de uma pessoa, de que os desejos de primeira ordem (que levam à ação, diferentemente de meramente sentidos) sejam ou se tornem das espécies que levam a ações que moldam ou produzem uma vida caracterizada por certa qualidade (pela participação em certa prática, ou pela relação adequada com determinado objeto de valor) que caracteriza uma vida realizada (boa, repleta de significado, bem vivida), e que é parcialmente constitutiva da identidade de alguém)" (LACEY, 1998, p. 40). Vividos e manifestados no comportamento do indivíduo ou grupo social, tais "desejos de segunda ordem" podem ser incorporados em instituições sociais ou na sociedade como um todo - daí a articulação dos valores pessoais com os valores sociais. Entre ambos há "uma relação estreita" (LACEY, 1998, p. 43), bem como entre os valores pessoais e aqueles articulados pelas instituições dominantes na sociedade. Nesta teia (em nada determinista, com certeza, mas dialética), observamos a possibilidade do "retorno" dos valores sobre as próprias crenças e desejos do indivíduo: se por um lado estes elementos modulam os valores exercitados na vida prática podendo institucionalizá-los ou transformá-los em valores sociais, por outro, esses mesmos valores sociais podem se voltar sobre os indivíduos, moldando suas crenças e desejos.
} 
científica acerca do nível de manifestação de tais valores por uma teoria, ou por teorias rivais, em vez de por meio da aplicação de um algoritmo ideal por cientistas individuais" (LACEY, 1998, p. 61). Os valores que assim se manifestam são, no dizer do autor, os valores cognitivos (como adequação empírica, consistência, simplicidade entre outros). Afirmar, então, a objetividade dos valores morais ou sociais e a existência de valores cognitivos, que servem como baliza no julgamento das teorias científicas, implica em afirmar a presença de valores no interior do discurso científico - e não apenas destes, mas também dos assim chamados valores cognitivos ou epistêmicos. Trata-se, em linhas gerais, daquilo que a filósofa da ciência Hellen Longino chama o "caráter social" da objetividade científica.

Assim, com base nas abordagens do tema feitas por Hellen Longino (1990) em Values and Objectivity e por Hugh Lacey (1998) em Valores e Atividade Científica, pretendemos apresentar, aqui, o discurso histórico acerca da histeria como uma teoria nosológica pautada por valores, sendo estes tanto sociais quanto cognitivos, cuja inter-relação íntima interroga a tese acerca da objetividade dos valores epistêmicos. A histeria afigura, assim, como um exemplo de teoria médicocientífica, na qual valores sociais (nomeadamente: valores políticos e religiosos que institucionalizaram uma diferença de gênero) influenciaram decisivamente ora a recusa da existência da entidade mórbida, ora sua descrição e tratamento. Tamanha foi a força dos valores sociais nas teorias etiopatológicas da histeria que, até mesmo na teoria psicanalítica, se ela já não é mais descrita como uma "doença das mulheres", ainda o continua sendo como "sofrimento do feminino".

O conceito histeria abrange várias acepções:

a) Histeria de conversão: grande crise de ataque convulsivo, com sintomas de conversão, paralisias, contraturas, corpo em arco de círculo, distúrbios da visão, alucinações, anestesias, dores, etc.

Na conversão histérica nenhum sintoma é típico, uma vez que seu contrário estará igualmente presente. No tocante ao humor: risos e choros, depressão e euforia, frieza de sentimentos e veemência da linguagem. No tocante à memória: amnésias e recordações detalhadas. No tocante aos sinais sensoriais: hiperestesia e anestesia segundo um recorte que não acompanha a anatomia nervosa, afasia e volubilidade, mutismo e atração pelos rumores, cegueira e alucinação, anorexia e bulimia, amenorréia e hipermenorréia. No tocante aos distúrbios motores: tique, bufonaria, convulsão epileptóide e paralisia, contratura (JULIEN, 1996, p. 245).

b) a psiconeurose histérica, objeto de estudo da psicanálise. Manifesta-se por Cad. de Pesq. Interdisc. em Ci-s. Hum-s., Florianópolis, v.14, n.104, p.67-84, jan/jun 2013 
sintomas diversos e pela inversão dos afetos (Dora, uma das pacientes tratadas por Freud, experimentou uma excitação sexual sob a forma não de desejo, mas de repugnância, deslocamento para a zona oral de um conflito sexual genital);

c) certo tipo de personalidade e de modo de relação, que utiliza a dramatização, a exuberância afetiva, a linguagem metafórica e superlativa, a erotização permanente, a sedução, etc.;

d) em razão da preponderância desse tipo de personalidade entre as mulheres, certa designação pejorativa do feminino; e

e) na linguagem comum, a "crise de nervos", a "cena".

Não obstante, a delimitação da doença histérica acompanhou as transformações da própria história da medicina. Fazer a história da histeria é atribuirIhe sintomas que não cessam de mudar. Não há relação necessária entre a histeria e os sinais que produz aos olhos dos espectadores e dos historiadores. No entanto, esses sintomas não se produzem ao acaso, ao contrário, parecem ser bem determinados segundo a chance que têm, em dado período, de chamar a atenção e despertar a inquietação, não da opinião pública em geral, mas dos especialistas que, por seu saber, são os esteios do poder político ou religioso: médicos, filósofos, teólogos, inquisidores.

\section{Na Antiguidade, a origem uterina da histeria}

A etimologia da palavra histeria aponta já para sua etiologia mais recuada: trata-se de uma doença do hystera, do útero.

A referência mais antiga a esta patologia encontra-se no Papiro de Kahun. ${ }^{3}$ Neste documento encontram-se as primeiras descrições de alguns dos sintomas supostamente relacionados com a histeria, que iam desde clinofilia, condição psiquiátrica caracterizada pela tendência a permanecer por um longo período de tempo deitado na cama, dores em vários órgãos e a impossibilidade de abrir a boca. Os egípcios acreditavam que todos esses sintomas teriam uma única causa: o útero.

\footnotetext{
${ }^{3}$ Não se trata de um papiro único, mas fragmentos de diversos papiros encontrados em Kahun, um antigo assentamento de construtores de pirâmides próximo à pirâmide de Al Lahun da $12^{\mathrm{a}}$ dinastia de Senusret II. Escritos em hierático, foram escavados por Flinders Petrie (1888-90), traduzidos e restaurados por F.L. Griffit e datam de 1900 ou 1800 a.C. ("O Papiro de Kahun: descrição e tratamento da histeria no Antigo Egito". Disponível em:

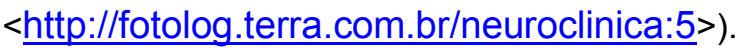


De acordo com o pensamento da época, o "útero erradio", acometido de inanição, deslocava-se através do corpo feminino prejudicando o funcionamento dos órgãos. Dessa forma, a medida terapêutica para esse transtorno era a inalação de substâncias fétidas ou fumigações vaginais para atrair o útero ao seu lugar de origem.

Os médicos da Antiguidade greco-romana continuaram a tratar a histeria como uma enfermidade do útero. Tal foi a força, até o século $X X$, dos textos atribuídos a Hipócrates e seus sucessores, Celso, Areteu e Galeno. Afinal, de onde vêm esses sintomas de convulsão, de "bola faríngica", de paralisia? Ocorreriam por causa de uma constrição e de uma sufocação que vem da migração do útero que sobe de baixo para cima. Platão (contemporâneo de Hipócrates) segue esta verve no Timeu (91C):

\footnotetext{
Nas mulheres, o que chamamos de matriz ou de útero é nela como um ser vivo tomado pelo desejo de fazer filhos. Quando permanece estéril durante muito tempo e apesar da estação favorável, o útero se irrita perigosamente; agita-se em todos os sentidos dentro do corpo, obstrui as passagens do ar, impede a inspiração, pondo assim o corpo nas piores angústias e the ocasionando toda sorte de outras doenças.
}

Nada mais móvel, então, que o útero; nada mais erradio que esse animal dentro do animal. Assim, o remédio preconizado na medicina da Antiguidade era fazer o útero errante voltar ao seu lugar supostamente natural por meio de relações sexuais, trabalhos manuais e gestações, as quais deveriam acalmar a atividade febril da cabeça, que no ócio e no devaneio triunfa muito facilmente sobre o "baixo". "Contra a gravidade, gravidez", bordão certamente moderno, mas que descreve bem a natureza da patologia na nosologia antiga. A histeria era caracterizada, então, como doença das virgens e das viúvas.

\section{Na Idade Média, a possessão demoníaca}

No final da Antiguidade, e a partir de Santo Agostinho, inverte-se a etiologia. Como a natureza já não é mais um princípio de ordem, o gozo do sexo não podia mais ser um remédio. 
mesma desordenada e enganosa em razão do mal introduzido por espíritos maus e demônios. A humanidade é o móbil de um combate entre Deus esse adversário chamado Satã. Nessa luta da ordem do espírito, os sintomas somáticos são, portanto, portanto, o sinal de um triunfo da influência das forças do mal (JULIEN, 1996, p. 246).

Por toda a Idade Média, com a Inquisição favorecendo um retorno ao sobrenatural, a histeria pendeu para o lado da possessão demoníaca e da bruxaria cujo objetivo era contestar o poder do senhor, tanto político quanto religioso. A feitiçaria testemunhava uma cumplicidade com forças maléficas, no momento de uma tentação que Deus permite para pôr o fiel à prova. A feiticeira, por consequência de um pacto com o demônio, tem poder sobre o corpo daquele ou daquela a quem quer fazer mal. A possessão se manifesta por uma influência de ordem erótica sobre o corpo do enfeitiçado: "visões, carícias, audácias de íncubos sobre as mulheres, de súcubos sobre os homens" (JULIEN, 1996, p. 246). Um sintoma predominante é a anestesia de certas zonas do corpo, a partir da qual surge a especialidade do "picador público", que põe o corpo à prova. A cura, de ordem espiritual, é obra de exorcistas que, com suas palavras, expulsam o demônio.

Mas, o decisivo é conseguir que o (a) enfeitiçado (a), ao mesmo tempo, aponte a feiticeira e se confesse em cumplicidade com ela, tendo em vista um julgamento de condenação. A execução da condenação cabe ao poder político. A morte é inevitável como punição que incide sobre o corpo; a alma estará salva se tiver havido confissão, condenada ao inferno, em caso contrário. A punição deve ser diante do povo, pois a possessão é interpretada como a contestação do poder do senhor. Numerosas histéricas foram queimadas em praça pública.

Dentre os manuais dos inquisidores, foi Malleus Maleficarum (O Martelo das Feiticeiras), de 1484, que, graças à sua precisão, serviu durante muito tempo como referência na luta contra a feitiçaria na Europa dos séculos XV à XVIII. O caráter teatral e contagioso dos sintomas histéricos esteve na origem de fenômenos tais como $\circ$ das freiras possessas do Convento de Loudun, ${ }^{4}$ dos convulsionários

\footnotetext{
${ }^{4}$ Em 1633 o convento das Ursulinas em Loudun, França, tornou-se o cenário do surto de algo que foi descrito como possessão demoníaca. As muitas freiras que viviam no convento passaram a mostrar todos os sinais de possessão, incluindo o falar em línguas e o agir de maneira histérica ao extremo. A afetação cresceu de tal maneira que praticamente todas as freiras pertencentes à instituição encontraram-se na mesma condição. A Madre Superiora do convento, Jeanne des Anges (Mme. de Béclier), dotada de um temperamento instável, parece ter contagiado as outras irmãs. Ela, uma freira chamada Claire e quatro outras delas foram as primeiras a serem "possuídas" pelos espíritos demoníacos. A situação espalhou-se pela cidade e causou tanto escândalo que o Cardeal Richelieu designou uma comissão para examinar o caso. Os "demônios" resistiram ao processo de exorcismo,

Cad. de Pesq. Interdisc. em Ci-s. Hum-s., Florianópolis, v.14, n.104, p.67-84, jan/jun 2013
} 
jansenistas de Saint-Médard, ${ }^{5}$ das bruxas de Salem e de Elisabeth de Ranfaing. ${ }^{6}$

\section{Na Idade Moderna, o nascimento da psiquiatria}

Com o Renascimento ocorre uma revivescência do interesse pela cultura greco-romana da Antiguidade. Nesse novo contexto, a histeria volta a ser considerada uma doença que depende de causas internas e naturais. Foi isso que permitiu o nascimento de uma ciência teórica e terapêutica. Essa busca de uma etiologia da histeria engendrou, a partir do século XVII, três correntes distintas.

A primeira delas foi a corrente organicista da Grã-Bretanha (Jorden, Burton e Cullen). A teoria uterina de Hipócrates foi contestada em nome da neurologia: a histeria decorreria de um distúrbio nervoso do cérebro. William Cullen (1710-1790), médico escocês, alcunhou o termo "neurose" num tratado de medicina publicado em 1777 (First Lines of the Practice of Physics), cuja segunda parte (Neurosis or Nervous Diseases) trata não só das doenças mentais ou "vesânicas" (designação genérica de diversas espécies de alienação mental ou loucura), como também da

mas sucumbiram temporariamente durante uma cerimônia mais intensa e impositiva, contudo, retornaram depois com uma violência ainda maior. A desconfiança recaiu, então, sobre o frade Urbain Grandier, o confessor do convento, acusado de ser o instigador de tudo. Ele foi preso e acusado de endemoninhar as freiras por meio de feitiçaria.

${ }^{5}$ Os jansenistas protagonizaram um fenômeno singular no cemitério de Saint-Médard, em Paris. Por volta do ano de 1727, seguidores daquela doutrina iam fazer preces no túmulo do diácono François Pâris, que professara o jansenismo e que fora reconhecidamente bom e caridoso. Algumas dessas pessoas, ao fazerem suas preces junto ao túmulo do diácono, eram tomadas de convulsões (daí o nome convulsionários). Outros diziam que ficaram curados de suas doenças. A cura dos doentes se operava pelo simples toque na pedra tumular ou pela poeira que encontravam ao redor e que tomavam com qualquer bebida ou aplicavam sobre as úlceras. Kardec relata esse fato na Revista Espírita de novembro de 1859. Era possível observar fenômenos estranhos nas pessoas durante as convulsões: a faculdade de resistir a pancadas tão terríveis que os corpos deveriam ficar esmagados; a de falar línguas ignoradas ou por eles esquecidas; um desdobramento extraordinário de inteligência: os mais ignorantes entre eles improvisavam discursos sobre a graça, sobre os males da Igreja, sobre o fim do mundo, etc.; a faculdade de ler o pensamento; postos em contato com os doentes, experimentavam as dores destes e exatamente nos mesmos lugares. A insensibilidade física produzida pelo êxtase deu lugar a cenas atrozes. A loucura chegou a ponto de realmente crucificarem vítimas infelizes, de lhes fazer sofrer todos os martírios da Paixão de Cristo. E essas vítimas solicitavam as terríveis torturas, designadas entre os convulsionários pelo nome de grande socorro. Como naquelas cenas de convulsões, a histeria desempenhava grande papel, e a indecência e a crueldade se mesclavam com o fanatismo; o arcebispo de Paris proclamou que aqueles, chamados milagres, eram falsos. Por isso, em 27 de janeiro de 1732, as autoridades proibiram a entrada no cemitério de Saint-Médard, o que levou um sarcástico a escrever no portão do cemitério: "Proíbe-se, em nome do Rei, que Deus faça milagres neste local". Os mesmos fanáticos passaram então a realizar suas convulsões em casas particulares, o que ainda durou até a Revolução Francesa. Na opinião de muita gente na época, o túmulo do diácono Paris foi o túmulo do jansenismo, tal a repercussão negativa daquelas cenas provocadas pelos convulsionários.

${ }^{6}$ Elizabeth de Ranfaing é acusada de ter assassinado um médico chamado Poirot em Nancy, em 1621, após ter sido "possuída" pelo demônio no convento que fundara (MONTER, 2007, pp. 98-115).

Cad. de Pesq. Interdisc. em Ci-s. Hum-s., Florianópolis, v.14, n.104, p.67-84, jan/jun 2013 
dispepsia, das palpitações cardíacas, da cólica, da hipocondria e da histeriaEnquanto no caso das neuroses "digestivas", "cardíacas" ou "estomacais" é reconhecida uma sede orgânica definida, na hipocondria e na histeria postula-se a existência de uma (no caso desta, no útero ou canal alimentar). O que ambos os grupos têm em comum, porém, é o fato de serem consideradas afecções funcionais (isto é, sem "inflamação" ou lesão estrutural do órgão afetado) e doenças do sistema nervoso.

Já com Thomas Sydenham (1624-1689), na Grã-Bretanha, e Philippe Pinel (1745-1826), na França, a histeria recebeu pela primeira vez um fundamento psíquico. Na verdade, parece ser atribuída a Sydenham a definição da histeria como uma doença mental. Em suas Dissertatio epistolaris, de 1682, Sydenham (lembrado também, entre outros feitos, pela descrição da Coreia Aguda ou dança-de-são-vito) descrevera a histeria como doença especificamente feminina, devendo ser reservada a designação hipocondria para os casos de histeria no homem. Pinel (considerado por muitos o pai da psiquiatria), por sua vez, como responsável pelo Hospício de Bicêtre, desenvolveu um método clínico sistemático para o estudo da alienação mental, que tinha como fundamento a observação ostensiva dos pacientes. O empirismo e o sensualismo residiam na base da abordagem. Em seguida, tratava-se de "ordenar a massa caótica de sintomas que se apresentam ao clínico" (Pessuti, 1994, p. 146 apud PEREIRA, 2004, p. 115). Tal tarefa classificatória era o início da implantação de um processo racional de aproximação do fenômeno estudado, mas não implicava supor que as entidades isoladas correspondiam a doenças biológicas expressas no campo mental. Ao contrário, para Pinel, a loucura era uma doença essencialmente mental e suas bases orgânicas são concebidas em uma relação dinâmica com o arcabouço anímico individual. Entre as diretrizes que adotara no tratamento dos alienados de Bicêtre estava a de introduzir no tratamento princípios que reduziriam a importância da lesão anatômica.

Como já não se trata mais de uma doença orgânica do cérebro, mas de uma desordem das paixões com consequências somáticas, a histeria passa a ser vista como passível de cura. Segundo Philippe Julien (1996, p. 248) ela passa a ser vista como uma "alienação mental", uma "afecção do espírito, que exige, portanto, um tratamento moral $^{7}$ ou psíquico".

\footnotetext{
${ }^{7} \mathrm{O}$ "tratamento moral" remonta a um dos princípios adotados por Pinel em Bicêtre, isto é, o de substituir a atitude brutal e repressiva para com os loucos por uma atitude compreensiva. Fundava-se Cad. de Pesq. Interdisc. em Ci-s. Hum-s., Florianópolis, v.14, n.104, p.67-84, jan/jun 2013
} 
Finalmente, a partir do século XVIII, distinguiu-se pouco a pouco uma terceira via, com Franz Anton Mesmer (1734-1815), na França, James Braid (1795-1860), na Grã-Bretanha e, sobretudo, Jean Martin Charcot (1825-1893), na Salpêtrière. Sob os nomes de magnetismo, de fluido ou de sugestionabilidade, eles mostraram o poder da hipnose sobre os sintomas histéricos. Para Charcot - que no Salpêtrière fez isolar, dentre as mais de quatro mil mulheres internadas, as histéricas das demais alienadas, e elegeu a histeria como seu objeto de pesquisa - o sintoma não é a expressão de uma emoção oculta, devendo ser reduzido a um conjunto de sinais, cada um dos quais só tem valor em sua relação com os outros. Foi então que o sintoma formou um quadro clínico do ponto de vista do neurologista. A histeria tem por etiologia e hereditariedade, isto é, uma degenerescência, mas os sintomas tem como causas ocasionais, agents provocateurs: queda de uma escada, palavras brutais, tapas ultrajantes e a voz do hipnotizador. Assim, pela sugestão hipnótica, este faz e desfaz o sintoma em virtude de uma clivagem da consciência.

\section{Na Psicanálise incipiente, o estatuto sexual do psiquismo}

Por influência de Charcot, o problema posto pela histeria ao pensamento médico e ao método anátomo-clínico reinante está na ordem do dia. A solução é procurada em duas direções: diante da ausência de qualquer lesão orgânica, referir os sintomas histéricos à sugestão, à auto-sugestão, e mesmo à simulação (com Babinski), ${ }^{8}$ ou dar à histeria a dignidade de uma doença como as outras, tão definida

na crença de que seria possível introduzir mudanças significativas no comportamento dos doentes por meio de atitudes humanas, mas firmes, da equipe técnica para com aqueles. Termos como "repressão", "intimidação", "doçura" e "filantropia" passam a ser encontrados no vocabulário técnico cotidiano e, em particular, nos textos de Pinel. Tal preocupação, contudo, não é uma inovação do próprio Pinel - tal tendência já é observada no trabalho de William Tuke, em York, e Haslan, no Hospital de Bethleen, em Londres. O que surge efetivamente como algo novo sob a influência do alienista francês é a associação dessa postura tolerante e humanista com o esforço de estudar racional e metodicamente o fenômeno da alienação (PEREIRA, 2004, p. 114).

${ }^{8}$ Em 1886, Joseph-François-Félix Babinski (1857-1932) publicou no primeiro número da Revista de Hipnotismo Experimental e Terapêutico um artigo intitulado "Pesquisas que servem para estabelecer que certos fenômenos nervosos podem ser transferidos de um paciente para outro sob a influência do ímã" (depois de estabelecer, como afirmava, "condições tais que qualquer ideia de simulação ou sugestão deve ser absolutamente afastada"). O artigo, que foi retomado no mesmo ano em Progresso Médico, se referia não só ao hipnotismo, mas também à metaloscopia de Burq, e até às teorias "fluídicas". Três anos depois, em Grande e pequeno hipnotismo, que foi publicado nos Archives de Neurologie, Babinski atacou violentamente a escola de Nancy, "o que, aliás, não exige longas argumentações, pois ela consiste essencialmente em negar tudo o que se afirma em Paris". Atacou também Bernheim, que "não atribui nenhuma importância à existência de fenômenos somáticos, que para ele são apenas obra de sugestão". Ora, a sugestão, "isto é, a ideia introduzida no cérebro" (Bernheim), constituía para os estudiosos de Nancy "a chave da hipnose", e quando, na

Cad. de Pesq. Interdisc. em Ci-s. Hum-s., Florianópolis, v.14, n.104, p.67-84, jan/jun 2013 
e concreta nos seus sintomas como, por exemplo, uma afecção neurológica (como pretendia o próprio Charcot).

O caminho seguido por Breuer e Freud (e, noutra perspectiva, por Janet) ${ }^{9}$ leva-os a ultrapassar essa oposição. Como Charcot, Freud considera a histeria como uma doença psíquica bem definida, que exige uma etiologia específica. Por outro lado, procurando estabelecer-lhe o "mecanismo psíquico", liga-se a toda uma corrente que faz da histeria uma "doença por representação" (LAPLANCHE; PONTALIS, 1983, p. 276). O esclarecimento da etiologia psíquica da histeria é paralelo das descobertas principais da psicanálise (inconsciente, fantasia, conflito defensivo e recalcamento, identificação, transferência, etc.).

É a histeria de conversão que está na origem da descoberta da psicanálise enquanto método de compreensão psicopatológica e de tratamento. Foi na medida em que Freud descobriu no caso da histeria de conversão traços etiopatogênicos importantes que a psicanálise pode referir a uma mesma estrutura histérica quadros clínicos variados que se traduzem na organização da personalidade e no modo de existência, e até quando não existem sintomas fóbicos e conversões patentes. Freud, assistindo às apresentações de doentes histéricas de Charcot, fica impressionado com a belle indifférence que elas manifestam por seu sofrimento. Suspeita primeiro de dissimulação de um segredo: o de uma sedução infantil traumática realmente ocorrida. Descobre em seguida que as histéricas "sofrem de

memorável sessão da Sociedade Neurológica do dia 7 de janeiro de 1901, Babinski propôs a sua nova "Definição da histeria", foi justamente à sugestão que ele se referiu: "O que caracteriza as perturbações primitivas [da histeria] é o fato de que é possível reproduzi-las por sugestão "com uma exatidão rigorosa, em certos pacientes, e fazê-las desaparecer sob a influência exclusiva da persuasão." E propôs o termo pithiatismo (do grego, eu persuado + curável), "para substituir vantajosamente" a palavra histeria, prestando ao mesmo tempo uma homenagem inconsciente a Peitó, divindade do cortejo de Afrodite, e, através dela, ao caráter sedutor da histérica. Deixando de assimilar histeria e hipnotismo e negando o fator afetivo, assimilava então histeria e sugestão, indo além do pensamento de Bernheim, que afirmava - com razão - que a sugestão ultrapassa amplamente o quadro da histeria (TRIPICCHIO, 2008).

9 Pierre-Marie-Félix Janet (1859-1947), egresso da École Normale Supérieure e posteriormente professor desta, da Sorbonne e do Collège de France, estudou as relações entre histeria, hipnose e automatismo psicológico. Defendeu em 1889 sua tese de psicologia intitulada L'Automatisme psychologique. Essai de psychologie experimentale sur les formes inférieures de l'activité humaine. Em 1892, após alguns anos de trabalho com Charcot no Salpêtrière, completa também sua tese de medicina, L'état mental des hystériques, onde expõe uma classificação das diferentes formas de histeria, distinguindo duas grandes categorias de neuroses: a histeria e a psicastenia (o que Freud chamaria neurose obsessiva). Janet descreve a histeria como um produto da sugestão psicológica (como a hipnose) caracterizada por um rebaixamento geral da tensão psicológica que, segundo ele, constituiria um "defeito pessoal indicador de deficiência constitucional". Em outras palavras, "é a estrutura da consciência do histérico que está fundamentalmente alterada, possuindo uma atitude para viver intensamente as imagens e para hipnotizar-se por elas" ("Histeria", Disponível em: $<$ http://www.portaldapsique.com.br/Dicionario/H.htm>).

Cad. de Pesq. Interdisc. em Ci-s. Hum-s., Florianópolis, v.14, n.104, p.67-84, jan/jun 2013 
reminiscências", ou seja, de um evento traumático que ficou sequestrado no inconsciente pelo recalcamento, não constituído em recordação, e que só pode, portanto, exprimir-se pela conversão, pela memória corporal. A causa da histeria deixaria de ser a hereditariedade, como afirmava Charcot, mas seria relacionada à dinâmica dos processos inconscientes e à psicossexualidade. Mais tarde, Freud desvinculará também histeria e conversão somática, relacionando-a a angústia, com ou sem sinais corporais.

Ao ir além de Breuer, Freud postula que esse traumatismo psíquico, causa da histeria, é uma experiência sexual prematura que surpreendeu o sujeito. De fato, esta não foi desejada, mas sofrida em decorrência de uma intervenção sedutora de um adulto (na maioria das vezes o pai) junto à criança. A histeria é, portanto, uma reação a posteriori à sexualidade enquanto "perversão recusada" (Carta 52 a Fliess). O sintoma é o próprio signo desse conflito.

A partir de 1897, abandonando a teoria da sedução traumática, Freud descobre - para escândalo geral - que a criança tem uma sexualidade e que os relatos posteriores de sedução pelo pai ocorrem no lugar das lembranças recalcadas de uma atividade sexual própria, e que os sintomas são o retorno do recalcado. $A$ histeria não passa, portanto, de um caso entre outros, desse fenômeno geral que é o infantilismo da sexualidade humana e das fantasias de desejo edipiano (incesto e parricídio). Esse infantilismo decorre do fato de que a sexualidade é traumática em si mesma, e não por acidente. Assim, o prôton pseudos - a primeira mentira, de que fala Freud a propósito de Emma e da histeria no Projeto de uma Psicologia (1895) é a única via pela qual originalmente se expressa, sob a forma enganosa da sedução paterna, a demanda inversa de ser o objeto para o qual se volta o desejo paterno. "Isso", escreve Philippe Julien, "a histeria não cessa de nos ensinar" (JULIEN, 1996, p. 248).

Postulando a independência entre afetos e representações, Freud pôde teorizar o conceito de pulsão, enquanto sedução interna por um impulso constante que deflagra os mecanismos de defesa do Eu. Na análise dos sonhos, descobre o pensamento do sonho (processo primário) e seu vínculo com o pensamento do histérico. Na teoria psicanalítica, uma crise histérica é a encarnação de um sonho: nela encontramos os mesmos mecanismos de condensação, deslocamento, simbolização e disfarce pela censura. Ela é a expressão de um conflito sexual que, não podendo ser elaborado pela via mental, efetua um salto do psíquico para o

Cad. de Pesq. Interdisc. em Ci-s. Hum-s., Florianópolis, v.14, n.104, p.67-84, jan/jun 2013 
corporal. Mas, é possível reencontrar, pelo método associativo psicanalítico, o seu trajeto fantasmático e simbólico.

\begin{abstract}
Assim, Freud descreve uma mulher histérica que com uma das mãos rasga e arranca suas roupas e com a outra as retém contra o corpo, exprimindo simultaneamente a luta entre a pulsão e a defesa, e a representação dramática de uma cena sexual, de uma cena primitiva, onde ela se figura como os dois parceiros dos dois sexos (SCHAEFFER apud DE MIJOLLA, 2005, p. 881).
\end{abstract}

$\mathrm{Na}$ esteira de Freud, os psicanalistas consideraram a neurose histérica e a neurose obsessiva como duas vertentes principais do campo das neuroses, "o que não implica que, como estruturas, elas não possam combinar-se neste ou naquele quadro clinico" (LAPLANCHE; PONTALIS, 1983, p. 276).

\title{
5. Desvelando valores sociais no discurso histórico acerca da histeria
}

O discurso histórico acerca da histeria associa, desde a Antiguidade, duas características: um déficit funcional de um órgão sexual e um déficit relativo às mulheres.

Como se justifica? Pelo desconhecimento de anatomia dos antigos? Não, porque, ainda que tivessem o conhecimento técnico a ponto de poder buscar no útero a sede orgânica da doença, não encontrariam nada (note-se que, modernamente, Cullen atribuiu à histeria uma origem cerebral, mas postulou a existência de uma disfuncionalidade no útero ou canal digestivo, vindo a reforçar o senso comum da descrição dos sintomas - "bola faríngica").

A origem da associação da histeria à mulher parece estar em outro lugar: na socialização de uma distinção de gênero que vê na mulher um ser mais suscetível aos ataques das paixões. É Hugh Lacey (1998) quem afirma, como vimos, que os valores - "desejos de $2^{\mathrm{a}}$ ordem" - podem tanto ser comunicados quanto tornar-se dominantes em determinada comunidade (inclusive, na comunidade científica), atingindo status objetivo. Note-se que foram homens os médicos e pensadores antigos a defender essa condição feminina, essa nosologia que se tornou standard (Hipócrates, Galeno, Platão). Parece reforçar essa tese o lugar que a mulher ocupava na democracia ateniense (se não em todo o mundo Greco-Romano): a mulher não era considerada cidadã, devendo ater-se aos afazeres domésticos. A 
mulher "ligada" a um homem pelo casamento permanecia em posição subalterna a ele. É atribuída a Aristóteles a máxima: "a mulher é naturalmente inferior ao homem, pois a fêmea é um macho malogrado".

Assim, uma distinção de gênero, carregada de valores (quais sejam: o homem é mais adaptado ao exercício da razão, das técnicas - inclusive a médica -, do governo da cidade e da coisa pública, enquanto a mulher, pela sua condição mais suscetível às paixões, deve ater-se ao âmbito privado do lar) justifica um discurso tanto cultural quanto médico que vê nessa "condição natural" da mulher a origem da histeria. Confirma-se assim, como pretende Hellen Longino (1990), que o discurso "objetivo" da ciência trata-se tão somente de uma "leitura de mundo" autojustificada, com grande poder explicativo e preditivo, mas em cujos valores que a sustentam não deixa de existir uma influência social, política, religiosa ou moral.

Já na Idade Média, o discurso histórico acerca da doença insere-se numa lógica de legitimação do poder político. A natureza já não é mais dotada de uma ordem passível de ser revelada, mas trata-se de um lugar de desordem e palco das tentações do inimigo de Deus, onde somente a iluminação divina (Agostinho) restauraria a harmonia. A histérica era ou o pobre joguete do inimigo maligno pelas mãos de uma feiticeira ou a própria engendradora de tais afrontas à autoridade divina. Daí é necessário que a iluminação divina fosse garantida por sua representante, a Igreja. Uma vez que o corpo - perecível e contaminado pelo pecado - era o palco de tais ataques, importava salvar a alma - elemento imortal através da confissão. A punição "purificadora" deveria acontecer diante do povo, pois a possessão e interpretada como a contestação do poder político.

$\mathrm{Na}$ Idade Moderna, ocorre uma interessante transformação no discurso valorativo acerca da histeria: nela assistimos ao advento da ciência moderna, a qual toma a física corpuscular newtoniana como seu padrão de cientificidade (lembrando que o tratado de Cullen, de 1777, era uma introdução à física). A medicina seguiu essa verve positivista: o que não pode ser provado empiricamente, previsto ou medido, é uma falácia. O que dizer, então, da histeria, cuja melhor tentativa de elaboração de uma etiologia anatômica foi a hipótese de uma doença nervosa com afetação do útero? Note-se que, novamente, a distinção de gênero se reafirma. Só resta acreditar, então, que se trata de dissimulação, fingimento, mentira, covardia diante das responsabilidades sociais.

Chama a atenção, nesta história da histeria, a persistente identificação da Cad. de Pesq. Interdisc. em Ci-s. Hum-s., Florianópolis, v.14, n.104, p.67-84, jan/jun 2013 
patologia ao feminino até mesmo no interior da psicanálise. "Histeria é uma manifestação de um sofrimento do "feminino", tanto na mulher quanto no homem", sentencia Jacqueline Schaeffer (DE MIJOLLA, 2005, p. 880). E Phillipe Julien reitera:

Por uma duplicidade que nunca se deixa agarrar, por uma mobilidade da própria máscara, o que o histérico procura de fato é confundir os hábitos de pensamento socialmente aceitos, perturbar os referenciais do saber universitário pondo à mostra seus limites, seus avatares e seus percalços. Daí vem a desconfiança constante desses especialistas, que não hesitam em identificar o histérico ao feminino (JULIEN, 1996, p. 245-246).

E mais: o sexual age como valor a desencadear prazer ou desprazer, e é remetido à própria natureza do psíquico: "psicossexualidade". Em Psicanálise "Silvestre", na reprovação que dirige ao médico que diagnosticara como causa da ansiedade da senhora divorciada a ausência de satisfação sexual, e à qual recomendara voltar para o marido, arranjar um amante ou "obter satisfação consigo mesma" (FREUD, 1910b/2000, s/p), Freud enumera os "erros científicos" do conselho do doutor. Este teria ignorado a compreensão ampliada que a psicanálise tem acerca da sexualidade ou, nas suas palavras, da "psicossexualidade". Esta coloca ênfase "sobre o ponto de que o fator mental na vida sexual não deve ser desdenhado ou subestimado" e que "os sintomas nervosos se originam em um conflito entre duas forças - de um lado a libido (...) e de outro (...) uma repressão que é sobremodo intensa" (FREUD, 1910b/2000, s/p). Ao mesmo tempo em que rechaça o corte que o jovem médico operara no conceito de sexualidade, reduzindoo ao coito, Freud sentencia: "Quem quer que não partilhe desde [sic] ponto de vista de psicossexualidade não tem o direito de expor teses psicanalíticas tratando da importância etiológica da sexualidade" (FREUD, 1910b/2000, s/p). Se até então a sexualidade era vista como questão de gênero, com Freud ela passa a integrar o estatuto mesmo do mental, e os sintomas histéricos passam a ser vistos como fruto de uma clivagem entre desejos inconscientes de natureza sexual e o discurso consciente, socializado. Nada mais característico de uma época, em que a manifestação dos impulsos sexuais eram flagrantemente reprimidos em nome de uma sociedade progressista e de moral puritana.

Por outro lado, a histeria sempre desafiou a medicina e a ordem social porque implica o sexual e o que é mais difícil de admitir, de reconhecer: o sexual feminino e o seu desejo de gozo sexual. Freud, em 1937, designa a 
'recusa do feminino' nos dois sexos como um 'fundo', um respaldo por causa da assimilação psíquica do feminino à castração. A histeria sintomática é uma doença do feminino recusado. Mais precisamente, a angústia do feminino que leva à sua recusa é a do impulso constante da libido e da violência que ela inflige ao $\mathrm{Eu}$, e a das grandes quantidades pulsionais que o sexo feminino exige (SCHAEFFER apud DE MIJOLLA, 2005, p. 881).

Charcot poderia então dizer que no século $\mathrm{XV}$ as coisas eram vistas exatamente da mesma maneira, sob o nome de possessão demoníaca e de enfeitiçamento. E Freud concluiu, quanto a essa clivagem:

Na realidade a Idade Média já havia escolhido essa solução ao admitir que a causa dos fenômenos histéricos era a possessão pelo demônio; bastava, portanto, substituir a terminologia religiosa daquela época obscura e supersticiosa pela terminologia científica dos tempos atuais (FREUD, 1893b/1991, p. 21).

Portanto, a adequação empírica, valor epistêmico de primeira grandeza no discurso científico moderno, não pode ser atestada como critério decisivo na escolha das teorias explicativas na história da histeria da Antiguidade até Freud: essas se baseavam muito mais em valores políticos, sociais e de gênero baseados na diferença sexual. Daí a resistência da medicina pré-freudiana em reconhecer a histeria no homem, definindo a psicopatologia masculina como "hipocondria". 


\section{REFERÊNCIAS}

BREUER, J; FREUD, S. Estudios sobre la Histeria (1895). In: Sigmund Freud - Obras Completas. Buenos Aires: Amorrortu, v. II, 1991.

DE MIJOLLA, A. (org.). Dicionário Internacional da Psicanálise: conceitos, noções, biografias, obras, eventos, instituições. Rio de Janeiro: Imago, 2005, verbete "Histeria", p. 880-881.

FERREIRA, A. P. B. Contextualização epistemológica da psicanálise de Freud. Dissertação de Mestrado defendida no Programa de Pós-Graduação em Filosofia da PUCPR. Curitiba, 2006.

FREUD, S. A Interpretação das Afasias. Lisboa: Edições 70, 1977.

FREUD, S. Algunas consideraciones con miras a un estudio comparativo de las parálisis motrices orgánicas e histéricas (1893a). In: Sigmund Freud - Obras Completas. Buenos Aires: Amorrortu, v. I, 1991.

FREUD, S. Bosquejos de la "Comunicación preliminar" de 1893 (1892). In: Sigmund Freud - Obras Completas. Buenos Aires: Amorrortu, v. I, 1991.

FREUD, S. Charcot (1893b). In: Sigmund Freud - Obras Completas. Buenos Aires: Amorrortu, v. III, 1991.

FREUD, S. Histeria (1888a). In: Sigmund Freud - Obras Completas. Buenos Aires: Amorrortu, v. I, 1991.

FREUD, S. La Interpretación de los Sueños (1900). In: Sigmund Freud - Obras Completas. Buenos Aires: Amorrortu, v. IV e V, 1991.

FREUD, S. Las Neuropsicosis de Defensa (1894). In: Sigmund Freud - Obras Completas. Buenos Aires: Amorrortu, v. III, 1991, p. 41-68.

FREUD, S. Más allá del principio de placer (1920). In Sigmund Freud - Obras Completas. Buenos Aires: Amorrortu, v. XVIII, 1992. 
FREUD, S. Projeto de uma Psicologia (1895). In: GABBI JUNIOR, O. F. Notas a Projeto de uma Psicologia. As origens utilitaristas da psicanálise. Rio de Janeiro: Imago, 2003.

FREUD, S. Prólogo à la traducción de H. Bernheim, De la suggestion (1888b). In: Sigmund Freud - Obras Completas. Buenos Aires: Amorrortu, v. I, 1991.

FREUD, S. Psicanálise "Silvestre" (1910b). In: Edição Eletrônica Brasileira das Obras Psicológicas Completas de Sigmund Freud. Rio de Janeiro: Imago, 2000.

FREUD, S. Pulsiones y destinos de pulsión (1915b). In: Sigmund Freud - Obras completas. Buenos Aires: Amorrortu, v. XIV, 1992, p. 105-134.

JULIEN, P. Histeria. In: KAUFMANN, P. (ed.). Dicionário Enciclopédico de Psicanálise. O legado de Freud e Lacan. Rio de Janeiro: Jorge Zahar, 1996, p. 245252.

LACEY, H. Valores e Atividade Científica. São Paulo: Discurso, 1998.

LAPLANCHE, J.; PONTALIS, J.-B. Vocabulário da Psicanálise. São Paulo: Martins Fontes, 1983, verbetes "Histeria", p. 275-276, "Neurose”, p. 377-380.

LONGINO, H. Values and objectivity. In LONGINO, H. Science as Social Knowledge. Princeton: Princeton University Press, 1990.

MONTER, W. A Bewitched Duchy. Lorraine and its Dukes, 1477-1736. Genebra: Droz, 2007, pp. 98-115.

PEREIRA, M. E. C. Pinel - a mania, o tratamento moral e os inícios da psiquiatria contemporânea. In Revista Latinoamericana de Psicopatologia Fundamental, ano 7, n. 3, set, p. 113-116. 2004.

SIMANKE, R. T. Memória, afeto e representação: o lugar do Projeto no desenvolvimento inicial da metapsicologia freudiana. In Revista Olhar, São Carlos, ano 7, n. 12/13, jan/jul e ago/dez, p. 12-40. 2005.

TRIPICCHIO, A. Babinski, Joseph-François-Félix (1857-1932). 2008. Disponível em: $<$ http://www.redepsi.com.br/portal/modules/wordbook/print.php?entrylD=155>. Acesso 
em: 22 dez. 2012.

Histeria. Disponível em: <http://www.portaldapsique.com.br/Dicionario/H.htm>. Acesso em: 21 jun. 2010.

O Papiro de Kahun: descrição e tratamento da histeria no Antigo Egito. Disponível em: <http://fotolog.terra.com.br/neuroclinica:5>. Acesso em: 21 jun. 2010.

Artigo:

Recebido em: 02/04/2012

Aceito em: 20/06/2013 